\title{
Effect and Safety of Iron Supplementation on Mild Thalassemia Complicated by Iron Deficiency in Late Pregnancy
}

\author{
Yanchuan Li1, Yanfeng Liu' ${ }^{2}$, Xue Li' ${ }^{1}$, Limin Hou' ${ }^{*}$ \\ ${ }^{1}$ Shaanxi Provincial People's Hospital, Xi'an 710068, Shaanxi Province, China \\ ${ }^{2}$ The Second Affiliated Hospital of Xi'an Medical College, Xi'an 710038, Shaanxi Province, China \\ *Corresponding author: Limin Hou, 837789191@qq.com
}

\begin{abstract}
Aim: To study the clinical effect and safety of iron supplementation in the treatment of mild thalassemia complicated by iron deficiency in late pregnancy. Methods: 376 patients with mild thalassemia complicated by iron deficiency in late pregnancy treated in our hospital from July 2019 to June 2021 were selected and recruited in the research group, and 200 normal pregnant women treated in the same period were selected and recruited in the control group. Hemoglobin (Hb), reticulocyte blood, red blood protein (RET he) level, ferritin (SF) level, soluble transferrin receptor (sTfR) level, adverse maternal and infant outcomes, etc. were analyzed. Results: There was no significant difference in the levels of SF, Hb, RET he and sTfR between the two groups before treatment. After treatment, the levels of SF, Hb, RET he and sTfR in the research group were significantly improved, which was statistically significant compared with the control group. The frequencies of intrapartum hemorrhage, premature delivery, stillbirth, hemorrhagic shock, and neonatal asphyxia in the research group were $289 \pm 47.88,36(9.57 \%), 0(0.00 \%), 25(6.65 \%)$, and $6(1.26 \%)$, respectively. The frequencies of intrapartum hemorrhage, premature delivery, stillbirth, hemorrhagic shock, and neonatal asphyxia in the control group were $284 \pm 46.99,7(3.50 \%), 0$ $(0.00 \%), 6(3.00 \%)$, and $0(0.00 \%)$, respectively. There were significant differences in preterm delivery and hemorrhagic shock, and there was no significant difference in other delivery outcomes. Conclusions: Under the premise of strictly controlling the iron reserve in pregnant women, continuous medication until the end of delivery may be conducive to the control of maternal thalassemia complicated by iron deficiency and the improvement of pregnancy outcome.
\end{abstract}

Keywords: Iron supplement; Late pregnancy; Mild thalassemia

Publication date: November 2021; Online publication: November 30, 2021

\section{Introduction}

Thalassemia is a genetic disease caused by hemoglobin gene defect. Its clinical manifestations mainly include hemolysis, hypochromic anemia, and reduced hemoglobin level ${ }^{[1]}$. Mild thalassemia mostly occurs in South China. Thalassemia during pregnancy may pose a serious threat to the health of pregnant women and fetuses. Pregnant women with mild thalassemia may have hemolytic anemia, accelerated heart rate, impaired myocardial function, thrombosis and other pregnancy complications during pregnancy, which may eventually affect placental oxygen transport, fetal development restriction, premature delivery and even abortion ${ }^{[2]}$. Thalassemia is mostly manifested in two main types, i.e., $\alpha$ type and $\beta$ types. The deletion of globin gene eventually leads to the occurrence of $\alpha$ type thalassemia. The mutation of globin gene causes $\beta$ type thalassemia accompanied by hemolytic anemia ${ }^{[3]}$. During pregnancy, pregnant women with mild thalassemia need obstetrician guidance and management, blood routine monitoring if necessary, and timely correction and treatment in case of anemia indications. At present, the screening methods for thalassemia 
mainly include blood routine examination, hemoglobin electrophoresis analysis and gene diagnosis. At the same time, combined with prenatal diagnosis methods such as umbilical cord blood puncture and amniocentesis, the birth of children with severe thalassemia is excluded ${ }^{[4]}$. For patients with thalassemia, iron supplementation should be carefully administered, and the cause of the patient should be determined first. If iron deficiency is caused by thalassemia, iron supplementation will lead to poor absorption of iron and iron poisoning. If the iron deficiency caused by iron deficiency anemia is combined with thalassemia, a large dose of iron supplements can be used.

\section{Data and methods}

\subsection{General information}

From July 2019 to June 2021, 376 patients with mild thalassemia complicated with iron deficiency in late pregnancy treated in our hospital were selected and recruited in the research group, and 200 normal pregnant women treated in the same period were selected and recruited in the control group. The age of patients with mild thalassemia complicated by iron deficiency in late pregnancy was 18-38 years old, with an average age of $29.22 \pm 2.33$ years, and the age of normal pregnant women in the control group was 19-40 years old, with an average age of $28.76 \pm 1.47$ years. There was no significant difference between the two groups.

The inclusion criteria of research group patients are: (1) patients who had their regular prenatal examination performed in our hospital; (ii) patients with normal psychological function who can comply with doctor's treatment; (iii) patients with mild thalassemia combined with iron deficiency; (iv) patients and their families who agreed to join the study.

Research group patient exclusion criteria include the following: (i) patients whose fetuses were found to have moderate to severe anemia during screening and examination; (ii) pregnant women who have a history of blood transfusion or bleeding during pregnancy; (iii) patients with incomplete clinical data.

\subsection{Methods}

Patients in the control group were supplemented with folic acid (0.4-0.8 mg/day) and iron (60-100 mg/day) from the early pregnancy. The patients of research group were given compound ferrous sulfate folic acid tablets ( $50 \mathrm{mg} /$ tablet), with a dosage scheme of 3 tablets for oral use and 3 times/day. At the same time, patients were instructed to take vitamin $\mathrm{C}(0.2 \mathrm{~g} /$ tablet $)$, with a dosage scheme of 3 times/day after meals until hemoglobin $\geq 120 \mathrm{~g} / \mathrm{L}$ or serum ferritin $>30 \mu \mathrm{g} / \mathrm{L}$.

\subsection{Observation indicators}

Hemoglobin (HB), reticulocyte blood, red blood protein (RET he), ferritin (SF), soluble transferrin receptor (sTfR), adverse maternal and infant outcomes, etc. are the observation indicators employed in this study.

\subsection{Statistical methods}

SPSS 23.0 statistical software was used for data analysis. If the measurement data comply with normal distribution and homogeneity of variance, the data are expressed as mean \pm standard deviation (SD) by variance test, and LSD test was used for intra-group comparison. If it does not conform to the normality or homogeneity of variance, it is expressed by the median and upper and lower quartiles, and the comparison is performed by nonparametric test. The count data were expressed by constituent ratio. Chi square test or F-exact probability method were used for comparison. $\mathrm{P}<0.05$ indicates that the difference was statistically significant. 


\section{Results}

\subsection{Comparison of SF, Hb, RET he and sTfR levels before and after treatment}

There was no significant difference in the levels of SF, Hb, RET he and sTfR between the two groups before treatment. After treatment, the levels of SF, Hb, RET he and sTfR in the research group were significantly improved, which was statistically significant compared with the control group. See Table 1.

Table 1. Comparison of SF, Hb, RET he and sTfR levels before and after treatment

\begin{tabular}{|c|c|c|c|c|c|}
\hline Group & & $\begin{array}{c}\text { Research group } \\
\quad(\mathbf{n}=376)\end{array}$ & $\begin{array}{c}\text { Control group } \\
(\mathbf{n}=200)\end{array}$ & $\mathbf{T}$ & $\mathbf{P}$ \\
\hline \multirow{2}{*}{ SF } & $\begin{array}{l}\text { Before } \\
\text { treatment }\end{array}$ & $8.79 \pm 3.23$ & $8.69 \pm 3.23$ & 0.3537 & 0.7237 \\
\hline & $\begin{array}{l}\text { After } \\
\text { treatment }\end{array}$ & $18.12 \pm 4.98$ & $9.01 \pm 3.14$ & 23.4996 & 0.0000 \\
\hline \multirow{2}{*}{$\mathrm{Hb}$} & $\begin{array}{l}\text { Before } \\
\text { treatment }\end{array}$ & $90.78 \pm 13.66$ & $91.12 \pm 13.54$ & 0.2853 & 0.7755 \\
\hline & $\begin{array}{l}\text { After } \\
\text { treatment }\end{array}$ & $97.84 \pm 15.98$ & $90.89 \pm 14.01$ & 5.1816 & 0.0000 \\
\hline \multirow{2}{*}{ Ret-He } & $\begin{array}{l}\text { Before } \\
\text { treatment }\end{array}$ & $20.45 \pm 2.98$ & $20.36 \pm 3.01$ & 0.3439 & 0.7311 \\
\hline & $\begin{array}{l}\text { After } \\
\text { treatment }\end{array}$ & $21.98 \pm 2.32$ & $20.66 \pm 3.06$ & 5.7998 & 0.0000 \\
\hline \multirow{2}{*}{ sTfR } & $\begin{array}{l}\text { Before } \\
\text { treatment }\end{array}$ & $7.36 \pm 2.66$ & $7.32 \pm 2.78$ & 0.1691 & 0.8657 \\
\hline & $\begin{array}{l}\text { After } \\
\text { treatment }\end{array}$ & $3.22 \pm 1.98$ & $7.40 \pm 2.46$ & 22.1266 & 0.0000 \\
\hline
\end{tabular}

Data are expressed as mean \pm SD.

\subsection{Comparison of adverse pregnancy outcomes}

The frequencies of intrapartum hemorrhage, premature delivery, stillbirth, hemorrhagic shock, and neonatal asphyxia in the research group were $289 \pm 47.88,36$ (9.57\%), 0 (0.00\%), 25 (6.65\%), and $6(1.26 \%)$, respectively. The frequencies of intrapartum hemorrhage, premature delivery, stillbirth, hemorrhagic shock, and neonatal asphyxia in the control group were $284 \pm 46.99,7(3.50 \%), 0(0.00 \%), 6(3.00 \%)$, and 0 $(0.00 \%)$, respectively There were significant differences in preterm delivery and hemorrhagic shock, and there was no significant difference in other delivery outcomes. See Table 2.

Table 2. Comparison of adverse pregnancy outcomes between the two groups

\begin{tabular}{lccccc}
\hline Group & $\begin{array}{c}\text { Intrapartum } \\
\text { hemorrhage } \\
(\mathbf{m L}, \text { mean } \pm \text { SD) }\end{array}$ & $\begin{array}{c}\text { Premature } \\
\text { delivery } \\
(\mathbf{n}(\boldsymbol{\%}))\end{array}$ & $\begin{array}{c}\text { Stillbirth } \\
(\mathbf{n}(\boldsymbol{\%}))\end{array}$ & $\begin{array}{c}\text { Hemorrhagic } \\
\text { shock } \\
(\mathbf{n}(\boldsymbol{\%}))\end{array}$ & $\begin{array}{c}\text { Neonatal } \\
\text { asphyxia } \\
(\mathbf{n}(\boldsymbol{\%}))\end{array}$ \\
\hline Research group $(\mathrm{n}=376)$ & $289 \pm 47.88$ & $36(9.57)$ & $0(0.00)$ & $25(6.65)$ & $6(1.26)$ \\
Control group $(\mathrm{n}=200)$ & $284 \pm 46.99$ & $7(3.50)$ & $0(0.00)$ & $6(3.00)$ & $0(0.00)$ \\
$\mathrm{X}^{2} / \mathrm{T}$ & 1.2009 & 12.8530 & - & 6.6900 & - \\
$\mathrm{P}$ & 0.2303 & 0.0003 & - & 0.0082 & - \\
\hline
\end{tabular}




\section{Conclusion}

In the physiological process of pregnancy, the blood volume of pregnant women gradually increases along with pregnancy length and fetal development. If the red blood cells and plasma do not increase in the same proportion, it can cause physiological anemia. The change of physiological anemia during pregnancy may induce mild thalassemia, aggravate anemia in pregnant women, affect maternal and fetal health, and even cause long-term adverse effects on newborns ${ }^{[5]}$. Clinically, pregnant women with mild thalassemia during pregnancy are generally divided into two types: with iron deficiency and without iron deficiency. Iron supplementation treatment should be considered in the former type, while iron removal treatment should be adopted in patients with the former type. Previous studies have shown that iron supplementation treatment for mild thalassemic pregnant women with iron deficiency in early pregnancy will aggravate reactions to pregnancy, such as vomiting of pregnancy, so iron supplementation intervention in early pregnancy is not recommended ${ }^{[6]}$.

In conclusion, under the premise of strictly controlling the iron reserve in pregnant women, continuous medication until the end of delivery may be conducive to the control of maternal thalassemia complicated by iron deficiency and the improvement of pregnancy outcome.

\section{Disclosure statement}

The authors declare no conflict of interest.

\section{References}

[1] Cheng J, 2021, Changes of Hemoglobin and Ferritin Levels During Pregnancy and Pregnancy Outcome in Patients with Mild Thalassemia. Jilin Medical Journal, 42(07): 1718-1719.

[2] Hong X, Yu H, Wu H, 2020, Study on Shengxuening Tablets to Improve the Anemia Degree of Pregnant Women with Mild Thalassemia. Modern Hospital, 20(07): 1065-1067.

[3] Peng B, Wang B, Zeng Q, et al., 2020, Diagnosis and Efficacy Evaluation of RET he on Iron Deficiency in Pregnant Women with Mild Thalassemia. China Tropical Medicine, 20(06): 552-556.

[4] $\mathrm{Hu}$ C, Yin C, 2020, Feasibility Study on Iron Supplementation for Pregnant Women with Mild Thalassemia Complicated with Iron Deficiency in Late Pregnancy. Journal of Preventive Medicine of the People's Liberation Army, 38(03): 40-42.

[5] Qiu T, Yin C, 2018, Study on Iron Metabolism of Pregnant Women with Mild Thalassemia. China Maternal and Child Health Research, 29(07): 853-856.

[6] He L, Gan H, Li M, 2015, Diagnosis and Treatment of Pregnancy Complicated with Mild Thalassemia. China Maternal and Child Health Care, 30(36): 6545-6547. 